controlled trials that investigate the efficacy and safety of QVA149 in patients with moderate-to-severe COPD.

Methods This overview includes data from 4 multicentre, double-bind, randomised controlled trials evaluating the effect of QVA149 110/50 $\mu \mathrm{g}$ versus IND $150 \mu \mathrm{g}$, GLY $50 \mu \mathrm{g}$, tiotropium (TIO) $18 \mu \mathrm{g}$ (open-label in the SHINE and SPARK studies; blinded in the BLAZE study), salmeterol/fluticasone (SFC) 50/ $500 \mu \mathrm{g}$, and placebo (PBO) in patients with moderate-to-very severe COPD. Outcomes reported here are lung function, transitional dyspnoea index (TDI), health status (via the St George's Respiratory Questionnaire [SGRQ]), and exacerbations over 6 weeks (BLAZE), 26 weeks (SHINE, ILLUMINATE), and 64 weeks (SPARK).

Results Data from 5138 patients were included in this overview. QVA149 provided statistically significant and clinically meaningful bronchodilation $(p<0.001)$ that was sustained throughout the treatment periods versus all comparators in all studies. QVA149 provided superior benefits versus TIO, SFC, and PBO with respect to TDI score in BLAZE and ILLUMINATE studies. At Week 64, QVA149 significantly improved SGRQ score $(p \leq 0.001)$ and significantly lowered the rate of all exacerbations compared with GLY and TIO in the SPARK study (Table). In addition, QVA149 reduced the rate of all exacerbations by $31 \%$ and significantly delayed the time to first exacerbation versus SFC in the ILLUMINATE trial.

Conclusion The results from the IGNITE trials demonstrate that superior improvements in lung function with once-daily QVA149 translate into meaningful therapeutic outcomes for patients with COPD as demonstrated by improved lung function, dyspnoea, health status, and reduced exacerbations.

\section{P236 SUPERIOR LUNG FUNCTION WITH ONCE-DAILY QVA149 TRANSLATES INTO IMPROVEMENTS IN PATIENT- REPORTED BREATHLESSNESS COMPARED WITH PLACEBO AND TIOTROPIUM IN COPD PATIENTS: THE BLAZE STUDY}

${ }^{1} \mathrm{~A}$ D'Urzo, ${ }^{2} \mathrm{DA}$ Mahler, ${ }^{3} \mathrm{M}$ Decramer, ${ }^{4} \mathrm{H}$ Worth, ${ }^{5} \mathrm{~T}$ White, ${ }^{5} \mathrm{VKT}$ Alagappan, ${ }^{6} \mathrm{~N}$ Gallagher, ${ }^{5} \mathrm{H}$ Chen, ${ }^{7} \mathrm{~K}$ Kulich, ${ }^{5} \mathrm{D}$ Banerij; ${ }^{1}$ Department of Family and Community Medicine, Faculty of Medicine, University of Toronto, Toronto, Ontario, Canada; ${ }^{2}$ Section of Pulmonology and Critical Care Medicine, Geisel School of Medicine, Dartmouth, Hanover, New Hampshire, USA; ${ }^{3}$ Department of Respiratory Medicine, University Hospital, Katholieke Universiteit, Leuven, Belgium; ${ }^{4}$ Departments of Pulmonology and Cardiology, Hospital Fürth, University Erlangen-Nürnberg, Fürth, Germany; ${ }^{5}$ Novartis Pharmaceuticals Corporation, East Hanover, NJ, USA; ${ }^{6}$ Novartis Pharmaceuticals UK Limited, Horsham, $U K_{i}{ }^{7}$ Novartis International $A G$, Basel, Switzerland

\subsection{6/thoraxjnl-2013-204457.388}

Introduction QVA149, a novel once-daily inhaled dual bronchodilator combining a fixed dose of the long-acting $\beta_{2}$ agonist indacaterol and the long-acting muscarinic antagonist glycopyrronium, has demonstrated improvements in dyspnoea versus its mono-components (indacaterol and glycopyrronium), tiotropium, and salmeterol/fluticasone using the interviewer-based Transition Dyspnoea Index (TDI) questionnaire. ${ }^{1,2}$ The BLAZE study evaluated the effect of once-daily QVA149 on patientreported dyspnoea versus placebo and blinded tiotropium in patients with moderate-to-severe chronic obstructive pulmonary disease (COPD).

Methods This was a 6 week, multicentre, randomised, blinded, double-dummy, placebo-controlled, 3-period, cross-over study. Patients aged $\geq 40$ years with moderate-to-severe COPD, postbronchodilator forced expiratory volume in 1 second $\left(\mathrm{FEV}_{1}\right)$ $\geq 30 \%$ and $<80 \%$ of the predicted normal, and post- bronchodilator $\mathrm{FEV}_{1}$ / forced vital capacity $<0.7$ were randomised to receive QVA149 110/50 $\mu$ g (via the Breezhaler ${ }^{\circledR}$ device) or placebo (via the Breezhaler ${ }^{\circledR} /$ HandiHaler ${ }^{\circledR}$ device) or blinded tiotropium $18 \mu \mathrm{g}$ (via the HandiHaler ${ }^{\circledR}$ device). The primary objective of the study was to evaluate the superiority of QVA149 versus placebo in the improvement of patient-reported dyspnoea as assessed by Self-Administered Computerised (SAC) version of the Baseline Dyspnoea Index (BDI)/TDI after 6 weeks of treatment. Other objectives included; standardised $\mathrm{FEV}_{1}$ area under the curve from 0 to 4 hours post-dose $\left(\mathrm{AUC}_{0-4} \mathrm{~h}\right)$; rescue medication use; safety and tolerability.

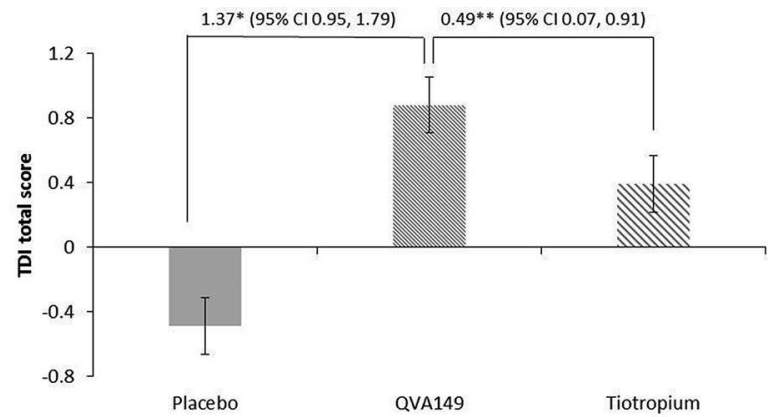

Data are LSM $\pm S E .{ }^{*} p<0.001 ; * * p=0.021$

\section{Abstract P236 Figure 1. TDI total score after 6 Weeks.}

Results Of the 247 patients (mean age 62.8 years) randomised, 191 completed the study. The SAC TDI total score was significantly improved with QVA149 compared with placebo and tiotropium after 6 weeks (figure). $\mathrm{FEV}_{1} \mathrm{AUC}_{0-4} \mathrm{~h}$ was significantly higher for QVA149 versus placebo and tiotropium at Day 1 and Week 6 (all $\mathrm{p}<0.001$ ). Rescue medication use was significantly lower with QVA149 versus placebo $(\mathrm{p}<0.001)$ and tiotropium $(\mathrm{p}=0.002)$. Incidence rate of adverse events was similar across all the treatment groups (QVA 149: 35.0\%; tiotropium: 35.5\%; placebo: $39.4 \%$ ).

Conclusion The BLAZE study provides evidence that the improved lung function with QVA149 translates into greater relief of breathlessness and improved patient-reported outcomes.

\section{REFERENCE}

1. Bateman et al. Eur Respir J. 2013 May 30.

2. Vogelmeier et al. Lancet Respir Med. 2013; 1:51-60.

\section{P237 COMPARISON OF COPD EXACERBATIONS WITH ONCE- DAILY QVA149 VERSUS TWICE-DAILY SALMETEROL/ FLUTICASONE COMBINATION: THE ILLUMINATE STUDY}

${ }^{1} \mathrm{C}$ Vogelmeier, ${ }^{2} \mathrm{ED}$ Bateman, ${ }^{3} \mathrm{H}$ Chen, ${ }^{3} \mathrm{D}$ Banerij; ${ }^{1}$ Department for Respiratory Diseases, University of Marburg, Marburg, Germany; ${ }^{2}$ Department of Medicine, University of Cape Town, Cape Town, South Africa; ${ }^{3}$ Novartis Pharmaceuticals Corporation, East Hanover, NJ, USA

\subsection{6/thoraxjnl-2013-204457.389}

Introduction Exacerbations are the most frequent cause of hospitalisation and death among patients with COPD. Combinations of long-acting bronchodilators maximise bronchodilation and may reduce the risk of exacerbations. QVA149, a once-daily dual bronchodilator containing the long-acting $\beta_{2}$ agonist (LABA) indacaterol and long-acting muscarinic antagonist (LAMA) glycopyrronium, improves lung function, breathlessness and rescue medication use compared with twice-daily salmeterol/fluticasone combination (SFC), in patients with moderate-to-severe COPD. ${ }^{1}$ 